
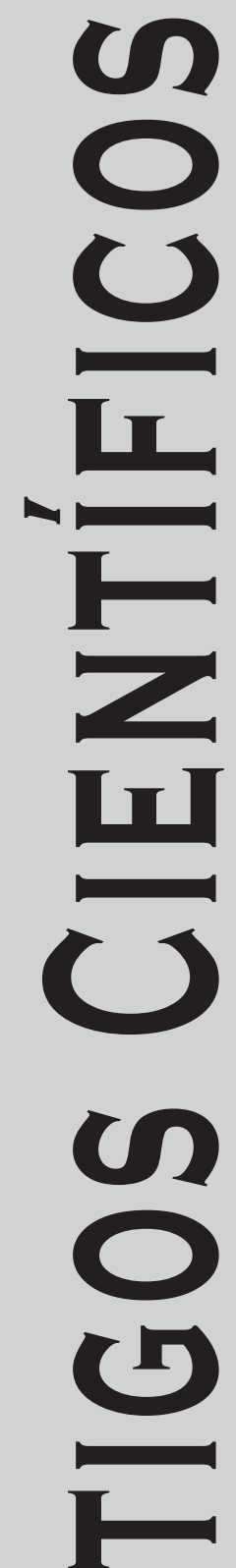
ac

Revista Música Hodie, Goiânia - V.14, 238p., n.1, 2014 


\title{
O Uso da Música Eletroacústica no Cinema Durante a Primeira Metade do Século XX Exemplificado no Caso de O Planeta Proibido (1956)
}

\author{
Juliano de Oliveira (FFCLRP / Universidade de São Paulo, Ribeirão Preto, SP) \\ juliano.oliveira@usp.br \\ Rodolfo Coelho de Souza (FFCLRP / Universidade de São Paulo, Ribeirão Preto, SP) \\ rcoelho@usp.br
}

\begin{abstract}
Resumo: A música eletroacústica no cinema está comumente associada a gêneros como ficção científica, suspense e terror. Para compreendermos as funções adquiridas por esse tipo de música no contexto audiovisual é preciso remontar aos primeiros usos de instrumentos eletrônicos e experiências com ruídos no cinema. Este artigo busca, portanto, descrever brevemente o desenvolvimento da poética eletroacústica na trilha sonora cinematográfica a partir do advento do cinema sonoro até o fim da primeira metade do século XX. Para tal, parte-se de uma breve contextualização, seguida da apresentação de algumas metodologias e conceitos que servirão de fundamentação para uma análise de caso do filme $O$ planeta proibido (Forbidden Planet, 1956).

Palavras-chave: Trilha sonora; Música eletroacústica; Espectromorfologia.

The Use of the Electroacoustic Music in Film During the First Half of the $20^{\text {th }}$ Century Exemplified in the Case of Forbidden Planet (1956)

Abstract: The electroacoustic music in the films is usually related to genres like science-fiction, suspense and horror. For understanding the functions performed by this type of music in the audiovisual context it is necessary consider the initial use of electronic instruments and noise experiments in the movies. The purpose of this article is, therefore, to describe the development of the electroacoustic poetics in soundtracks of the first half of the $20^{\text {th }}$ century. For that, we begin with a short contextualization followed by the explanation of some methodologies and concepts that will support the case analysis of the film Forbidden Planet (1956).
\end{abstract}

Keywords: Soundtrack; Electroacoustic music; Spectromorphology.

\section{Introdução}

Poucos anos após o advento do cinema sonoro ${ }^{1}$ e antes mesmo do surgimento da música concreta, em 1948 na França, técnicas rudimentares de manipulação de ruídos, semelhantes às utilizadas nos estudos de Pierre Schaeffer, já eram empregadas na trilha sonora cinematográfica. Parte dessas técnicas provinham de experiências de manipulação sonora com fonógrafos ou registros ópticos, cujo resultado era utilizado, posteriormente, na sonorização de filmes. Dziga Vertov foi um dos diretores mais originais e radicais na utilização do ruído, manipulado ou não, como elemento expressivo em suas obras. Em Entusiasmo - Sinfonia do Donbass (Entuziazm, 1931), seu primeiro filme sonoro, Vertov realizou experiências através de técnicas de manipulação de ruídos, como aumento e diminuição de velocidade, reversão etc, semelhantes às que, dezessete anos depois, seriam empregadas pelo criador da música concreta em suas primeiras composições. Entre outras coisas, Entusiasmo cumpriu, na prática, alguns dos postulados defendidos anos antes por Eisenstein, Pudovkin e Alexandrov na "Declaração sobre o futuro do cinema sonoro", em que os autores propunham o tratamento contrapontístico entre sons e imagens como alternativa ao uso banalizado do som como mera representação naturalista do conteúdo imagético (EISENSTEIN, 2002, p. 225-227). Outras experiências sonoras com ruídos nessa época provinham da animação direta, que consistia em desenhar diretamente ou simplesmente colar objetos sobre a película fílmica. Norman McLaren foi um dos mais notáveis artistas a utilizar a técnica da animação direta, tanto nas imagens quanto na trilha sonora de seus 
filmes. Em Synchromy (1971), uma de suas obras mais expressivas, ele utiliza as mesmas formas geométricas da imagem para a geração do som e obtém, com isso, resultados surpreendentes (IAZZETTA, 2009, p. 143).

Na versão cinematográfica de 1932 do clássico O médico e o monstro, o diretor Rouben Mamoulian recorreu à animação direta, por meio de desenhos criados com luz incidida sobre a película, para criar um som inusitado, semelhante ao produzido por um sintetizador eletrônico. A sonoridade sintética foi utilizada para acompanhar a cena da primeira transformação do Dr. Jekyll em Mr. Hyde. Segundo Hayward (2004) este pode ser considerado um dos tratamentos sonoros mais experimentais realizados em um filme de ficção científica no período precedente à Segunda Guerra Mundial.

Na mesma época, Odna (1931) se torna o primeiro filme a utilizar o theremin na trilha sonora. O longa-metragem soviético teve sua música composta por Dmitri Schostakovich, que soube habilmente fundir o som do instrumento eletrônico à malha orquestral e obter um resultado interessante. Nos anos seguintes, durante a década de 1930, os instrumentos eletrônicos e as experiências sonoras em geral encontraram pouco espaço nas trilhas sonoras cinematográficas. O theremin e o órgão Novachord, da Hammond Company, foram os instrumentos eletrônicos mais utilizados em trilhas sonoras dos anos 1930 e 1940. De modo geral, esses instrumentos estavam confinados a temáticas fílmicas que envolviam algum grau de anormalidade, como distúrbios psicológicos, estados alterados de consciência e criaturas bizarras. Após o theremin ser usado como instrumento solista nas cenas de sonho de A mulher que não sabia amar (Lady in the Dark, 1944), dois filmes, em especial, foram responsáveis pela consolidação do instrumento com temas psicológicos: Quando fala o coração (Spellbound), dirigido por Hitchcock, que trata do drama de um personagem com problemas psicológicos; e O farrapo humano (The Lost Weekend), dirigido por Billy Wilder, cujo personagem principal é um alcoólatra. Ambos os filmes foram musicados por Miklós Rósza; o theremin atua como solista e está associado com os distúrbios dos personagens principais.

Durante a segunda metade da década de 1940, o ruído havia se libertado de seu compromisso naturalista e seu potencial expressivo passou a ser cada vez mais explorado. Cidadão Kane (1944) foi um marco do cinema mundial e pode ser considerado uma obra-prima sob diversos aspectos. Em relação à trilha sonora, além da peculiar música composta por Bernard Herrmann, a formação e vasta experiência com o rádio permitiu a Orson Welles transportar sua concepção sonora para o cinema e utilizar o ruído de maneira original e criativa. Destarte, na década de 1940 o cinema abriu seus ouvidos gradativamente ao vasto universo das sonoridades ruidosas. Segundo Carrasco (2009, p. 170):

[Nos anos 40] o ruído seria descoberto como sonoridade expressiva, não sendo usado, apenas, como complemento naturalista da imagem. Em outras palavras, começava a se desenvolver uma poética do ruído que o aproximava da música como sonoridade expressiva. Por outro lado, a música descobre-se, cada vez mais, como sonoridade, aproximando-se do ruído.

Durante a crise do cinema norte-americano nos anos 1950, a busca por soluções de baixo custo e o anseio por novas estéticas contribuíram para que experiências da vanguarda musical, dentre elas a música eletroacústica, e instrumentos eletrônicos invadissem a trilha sonora do cinema. Esse também é o período em que a ficção científica se consolidou como gênero cinematográfico norte-americano e, portanto, nessa época, os instrumentos eletrônicos passaram a se associar também a filmes cuja temática envolvia experiências científicas mal sucedidas, invasões de seres alienígenas e viagens espaciais. O primeiro fil- 
me a explorar esse tipo de associação foi Da Terra à Lua (Rocketship X-M, 1950), com trilha musical composta por Ferde Grofé e orquestração de Albert Glasser. O pioneirismo da trilha musical de Da Terra à Lua está no fato de Grofé haver utilizado um órgão Novachord e um theremin, juntamente com a orquestra, para sequências que se passam no espaço e apenas uma orquestra tradicional para as cenas na Terra. No ano seguinte, este recurso foi refinado em $O$ dia que a Terra parou (1951), onde Bernard Herrman recorreu a técnicas de manipulação com tape magnético e uma instrumentação inusitada - em um estilo repleto de politonalidade e polirritmia que alude a Charles Ives e Stravinsky - que contrapunha instrumentos eletrônicos e orquestrais. As sonoridades eletrônicas - que incluem dois theremins, dois órgãos Hammond, um contrabaixo elétrico, um violino elétrico, um violoncelo elétrico, três vibrafones e uma guitarra elétrica - foram associadas aos aspectos alienígenas do personagem Klatuu (representado pelo ator Michael Rennie) enquanto a música orquestral se associava às suas características humanas.

Talvez o melhor exemplo de uso sistemático de música eletroacústica na trilha sonora de um filme da década de 1950 tenha sido o caso de O Planeta Proibido (Forbidden Planet, 1956), dirigido por Fred Wilcox e com tonalidades eletrônicas compostas pelo casal Louis e Bebe Barron. O Planeta Proibido é considerado o primeiro filme da história do cinema a possuir uma trilha sonora, incluindo música e efeitos sonoros, totalmente eletrônica. Curiosamente, o alto grau de experimentalismo fez com que a trilha do filme não fosse reconhecida como sendo música. Desse modo, foi utilizada nos créditos a denominação tonalidades eletrônicas. Esse filme, em especial, nos interessa pelo pioneirismo e originalidade com que o som foi tratado e, portanto, será mais detalhadamente analisado ao final desse artigo.

\section{Metodologias de análise}

A seguir apresentaremos alguns conceitos e metodologias que julgamos adequados para a análise de caso que se seguirá. Primeiramente, descreveremos o Método das Máscaras, tal como definido por Chion (2011). Este método ajudará a compreender, tanto quanto possível, a contribuição individual da trilha sonora para a obra fílmica. Em seguida, definiremos brevemente os conceitos de som diegético e som extradiegético baseados na teoria de Claudia Gorbman. Por último, lançaremos mão da tipologia e morfologia espectral de Denis Smalley como forma de classificar em tipos básicos os objetos sonoros que constituem a trilha do filme.

\subsection{O Método das máscaras}

O método das máscaras, tal como é denominado por Michel Chion (2011), consiste em analisarmos separadamente o conteúdo visual e sonoro de uma cena, sequência ou filme. Com isso, se busca evitar ao máximo a influência de um sentido sobre o outro, evitando, assim, análises precipitadas e se atendo às contribuições individuais de cada mídia à significação geral da obra. Chion sugere que se inicie a partir da observação dos elementos sonoros e visuais separadamente para, em seguida, juntar os dois elementos, conservando, assim, "uma escuta e um olhar fresco e novo e preparar a surpresa do encontro audiovisual” (CHION, 2011, p. 146). 


\subsection{A diegese}

Claudia Gorbman parte das definições de Etienne Souriau e Gérard Genette e transfere para o cinema o conceito de diegese como sendo "a narrativa implicada no mundo espaço-temporal das ações e personagens" (GORBMAN, 1987, p. 21). Em relação ao som, a diegese representa todo o fenômeno sonoro que faz parte da trama narrativa do filme e pode ser percebido pelo personagem. Assim, em síntese, temos:

- Som diegético: aquele proveniente do contexto onde se passa a narrativa fílmica. Exemplo: o som de um rádio ou TV que se encontra no espaço onde se passa a cena.

- Som extradiegético: é o som que não faz parte do contexto fílmico. É a famosa "música incidental" ou a voz de um narrador, por exemplo.

Gorbman (1987, p. 22) descreve ainda uma terceira categoria, que corresponde ao som metadiegético e representa o universo sonoro que se passa nos pensamentos, na memória, ou evoca as emoções ligadas a uma lembrança antiga de algum personagem. Segundo a autora, a música é o único elemento que aparece extensivamente na narrativa fílmica tanto em contexto diegético como extradiegético e, com frequência, cruza livremente as fronteiras entre eles. Embora a classificação da música e, de modo geral, de todo o som de um filme, nas duas categorias supracitadas - diegético e extradiegético - possam resultar em uma classificação redutível - haja vista a infinidade de exemplos em que essa classificação resulta paradoxal - o mérito de tal classificação em relação à música está no fato de que a compreensão da flexibilidade dela em relação ao contexto fílmico contribui para o reconhecimento das diferentes funções que ela pode assumir: temporal, espacial, dramática, estrutural, denotativa, conotativa etc., todas no fluxo diacrônico do filme e nos vários níveis simultâneos de interpretação (OLIVEIRA, 2012, p. 75).

\subsection{A tipologia espectral de Denis Smalley}

A ausência de uma terminologia consensual entre compositores e analistas é, ainda hoje, um dos principais obstáculos que se colocam para a análise de música eletroacústica. O Esboço de um solfejo concreto (Esquisse d'un solfège concret, 1952) seguido do Tratado dos objetos musicais (Traité des objets musicaux, 1966) e do Solfejo do objeto sonoro (Solfège de l'objet sonore, 1967), todos propostos por Pierre Schaeffer, foram as primeiras tentativas de apresentar uma taxonomia que tornasse possível o solfejo da música eletroacústica. Smalley concebeu a espectromorfologia, a princípio, como uma reformulação e simplificação da teoria schaefferiana, complementando esta, no entanto, na medida em que lançou as bases para uma interessante teoria do movimento sonoro.

A tipologia espectral de Smalley admite três tipos básicos de espectro: a nota, o nó e o ruído. A nota pode ser definida como o som cuja altura pode ser facilmente identificável. Esta, por sua vez, se subdivide em 3 partes: 1) a nota tradicional, que é centrada na percepção da fundamental; 2) a nota de espectro harmônico, onde é possível reconhecer uma altura definida, entretanto, o espectro harmônico ganha destaque em relação à fundamental; 3) a nota de espectro inharmônico, cuja relação entre os harmônicos não consistem em uma relação de números inteiros, como os sinos, por exemplo. O nó está situado entre a nota e o ruído. Geralmente ele resiste à identificação de altura, no entanto, é possível perceber um centro onde os harmônicos gravitam. O espectro de um prato suspenso pode ser classifica- 
do como nó. O ruído, por sua vez, se caracteriza pela impossibilidade de se determinar qualquer tipo de altura. Ele se subdivide em granulado e saturado, no entanto, a linha limítrofe de distinção entre um e outro é bastante tênue.

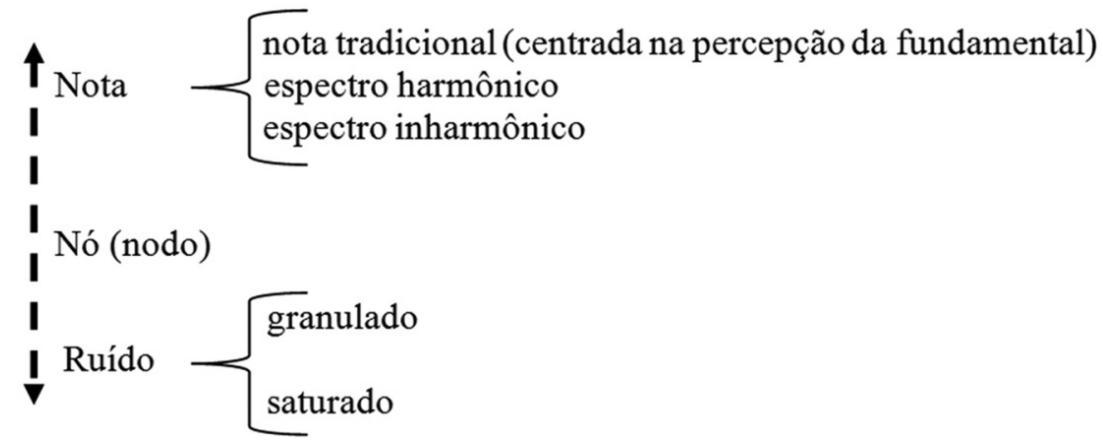

Gráfico 1: Tipologia espectral, segundo Smalley (1986, p. 65).

A morfologia consiste em descrever o comportamento de um espectro sonoro no tempo. Smalley (1986) identifica três arquétipos morfológicos básicos:

1) ataque-impulso: um ataque brusco seguido de um rápido decaimento, como um estalo ou batida de palmas;

2) ataque-decaimento: é formado por um ataque seguido de um decaimento lento. $\mathrm{O}$ ataque-decaimento se subdivide ainda em aberto, cujo decaimento é bastante lento, e fechado, cujo decaimento é relativamente breve.

3) continuação gradual: possui ataque e decaimento lentos, o que faz com que nossa atenção se concentre na fase intermediária do som. As notas longas dos instrumentos de cordas friccionadas ou sopros são exemplos desse arquétipo.

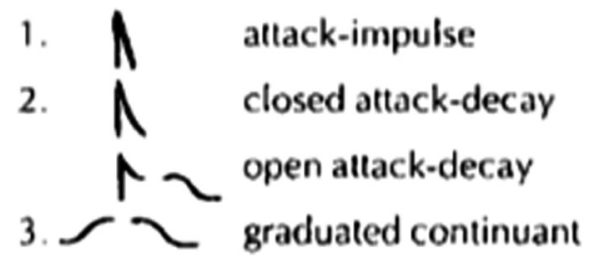

Figura 1: Arquétipos morfológicos básicos segundo Smalley (1986, p. 69).

Partindo dos três arquétipos morfológicos básicos, por meio de combinações e variações, é possível gerar outras morfologias. Smalley (1986) definiu os demais tipos morfológicos como modelos morfológicos, cadeias morfológicas e ataque-eflúvio contínuo, esta última um tipo específico de cadeia morfológica criada pela repetição do arquétipo ataque-impulso.

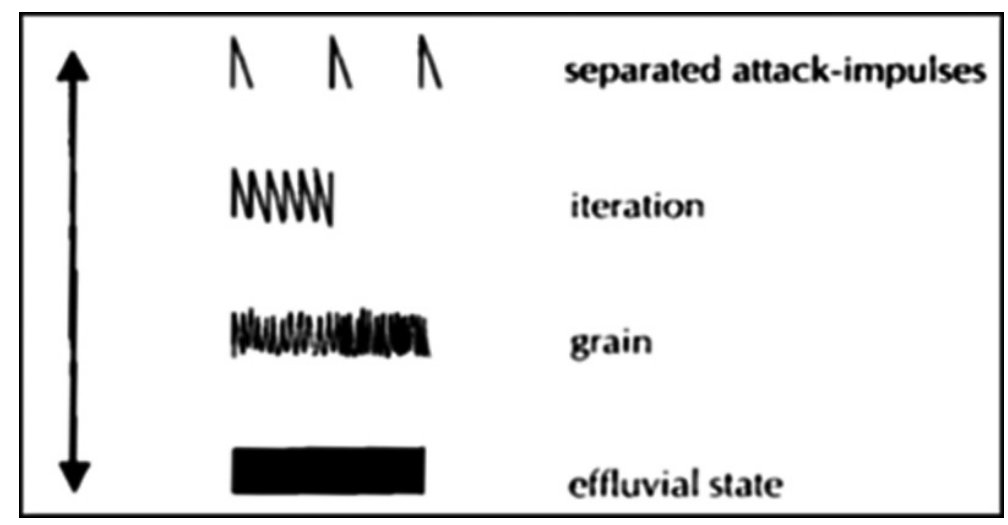

Figura 2: Ataque-eflúvio contínuo segundo Smalley (1986, p. 72). 


\section{Análise de caso: 0 planeta proibido}

O planeta proibido se insere na literatura cinematográfica como um dos clássicos da ficção científica da década de 1950. Ademais, o alto grau de originalidade faz de sua trilha sonora ${ }^{2}$ um dos melhores exemplos de uso de música eletroacústica no cinema desse período. A trilha sonora foi composta por meio de circuitos eletrônicos rudimentares criados por Louis Barron para a geração de sons que, posteriormente, eram manipulados por meio de tape magnético em seu estúdio particular em Nova Iorque. O casal Louis e Bebe Barron mixava diversos tracks diferentes utilizando vários gravadores. A sincronia entre os tapes era feita manualmente, contando até três, e então pressionavam os botões de playback simultaneamente. Conforme Holmes destaca, a sincronização precisa não era vital para a criação de suas "atmosferas sonoras" (HOLMES, 2008, p. 86).

Segundo Wierzbicki (2005, p. 32), o equipamento no qual os Barron produziram seus sons eletrônicos incluiu resistores, válvulas, capacitores, indutores e semicondutores. Eles possuíam osciladores capazes de gerar onda senoidal, quadrada e dente de serra e filtros construídos por eles próprios.

Para processarem os sons antes de gravarem no tape, eles tinham câmaras de reverberação acústica e uma assim chamada "plate reverb unit", uma placa de metal em uma mola suspensa que vibrava em resposta a um sinal elétrico e então convertia as vibrações em sinais mais complexos. (WIERZBICKI, 2005, p. 32)

O filme se passa no final do século XXIII e trata de um grupo de astronautas que é enviado ao planeta Altair IV para resgatar a tripulação da nave Belerephon, enviada vinte anos antes. Ao chegarem ao planeta misterioso os astronautas encontram o único sobrevivente da expedição anterior, o doutor em ciências e filólogo Edward Morbius (ator - Walter Pigdeon), sua filha Altaira (atriz - Anne Francis) e o robô Robby, criado pelo Dr. Morbius durante sua permanência no planeta. Após alguns dias, fenômenos estranhos começam a acontecer e a tripulação é dizimada aos poucos por um monstro invisível. Mais tarde descobre-se que tal monstro é fruto da materialização do Id (uma referência à teoria psicanalítica de Sigmund Freud) do Dr. Morbius e, para destruí-lo, seria preciso matar o próprio Dr. Morbius.

A fim de possibilitar uma visão geral das técnicas composicionais e das contribuições da trilha sonora, serão selecionados os materiais mais relevantes para efeito de análise. Portanto, optamos por 5 fragmentos musicais: a música dos créditos iniciais e os quatro leitmotivs que se relacionam, respectivamente, com os seguintes personagens:

1) Robby, o robô criado pelo Dr. Morbius;

2) Monstro do Id, a materialização do inconsciente do Dr. Morbius;

3) Altaira, filha do Dr. Morbius;

4) Krells, os antigos habitantes do planeta Altair IV.

\subsection{Música dos créditos iniciais}

Enquanto a maior parte da música de O planeta proibido foi criada a partir de materiais sonoros gerados por um ou mais circuitos eletrônicos e mantidos relativamente ininterruptos por todo o track, a música dos créditos iniciais é baseada em síntese temática uma herança da abertura operística - e é formada de uma bricolagem de vários materiais que permearão o filme. 
Embora grande parte da trilha sonora seja composta com base em texturas e gestos atonais, é possível abstrair melodias, estruturas harmônicas e sintaxes tonais em determinados momentos. O primeiro material motívico (0"-14”) se apresenta como música extradiegética, simultaneamente às imagem da marca registrada da produtora MGM (um leão rugindo). Este motivo é formado por duas melodias com sonoridade eletrônica, em registro agudo, possivelmente gerada a partir de onda senoidal. A primeira possui timbre semelhante ao de uma flauta e arquétipo espectromorfológico continuação gradual. A segunda possui o arquétipo ataque-decaimento e timbre semelhante a uma marimba mesclada com sino. A nota inicial delineia um gesto melódico que parte de Ré bemol $5^{3}$, realiza um intervalo de terça menor abaixo e é seguido de uma terça menor acima da tonalidade inicial. A harmonia implicada nessa relação de terças menores constitui um acorde diminuto, caracterizado pela instabilidade tonal que sugere a tensão e o mistério que predominam na abertura e permearão todo o filme. Aos 8 segundos, o Ré5 bemol é substituído pelo Dó4 como nota priorizada. Um terceiro som parte de Dó4 e realiza um glissando descendente, com vibrato, enquanto uma segunda melodia se contrapõe na região grave. Nesse momento, vemos o espaço sideral sendo cruzado pelo cruzador C57D, a nave na qual os astronautas viajam. Logo, o som com vibrato ouvido anteriormente é sincronizado à imagem da nave. Passamos a associar, então, a sonoridade eletrônica, a princípio extradiegética, ao objeto voador e, portanto, a música passa a ser interpretada diegeticamente como efeito sonoro. A ambiguidade diegético/ extradiegético - que, aliás, também pode ser representada em alguns momentos sob a forma efeito sonoro/música - exemplificada na cena supracitada, estará presente em todo o filme e evidencia, assim, as limitações dessa classificação dicotômica. Entretanto, a adoção de tais categorias aqui não busca limitar em dois polos opostos as inúmeras possibilidades de relacionamento entre som e imagem, mas, apenas partir delas como ferramentas que evidenciam a multiplicidade de significados que a trilha sonora adquire a partir do contraponto com as imagens.

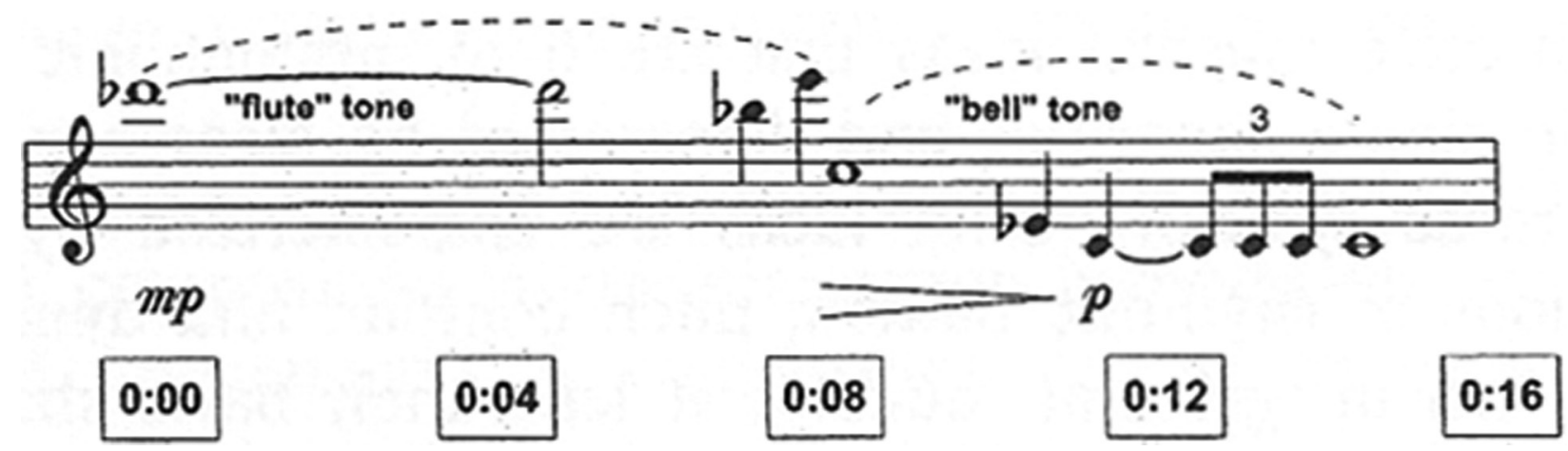

Figura 3: Redução do primeiro grupo motívico da música dos créditos iniciais de O Planeta Proibido, segundo Wierzbicki (2005, p. 66). 


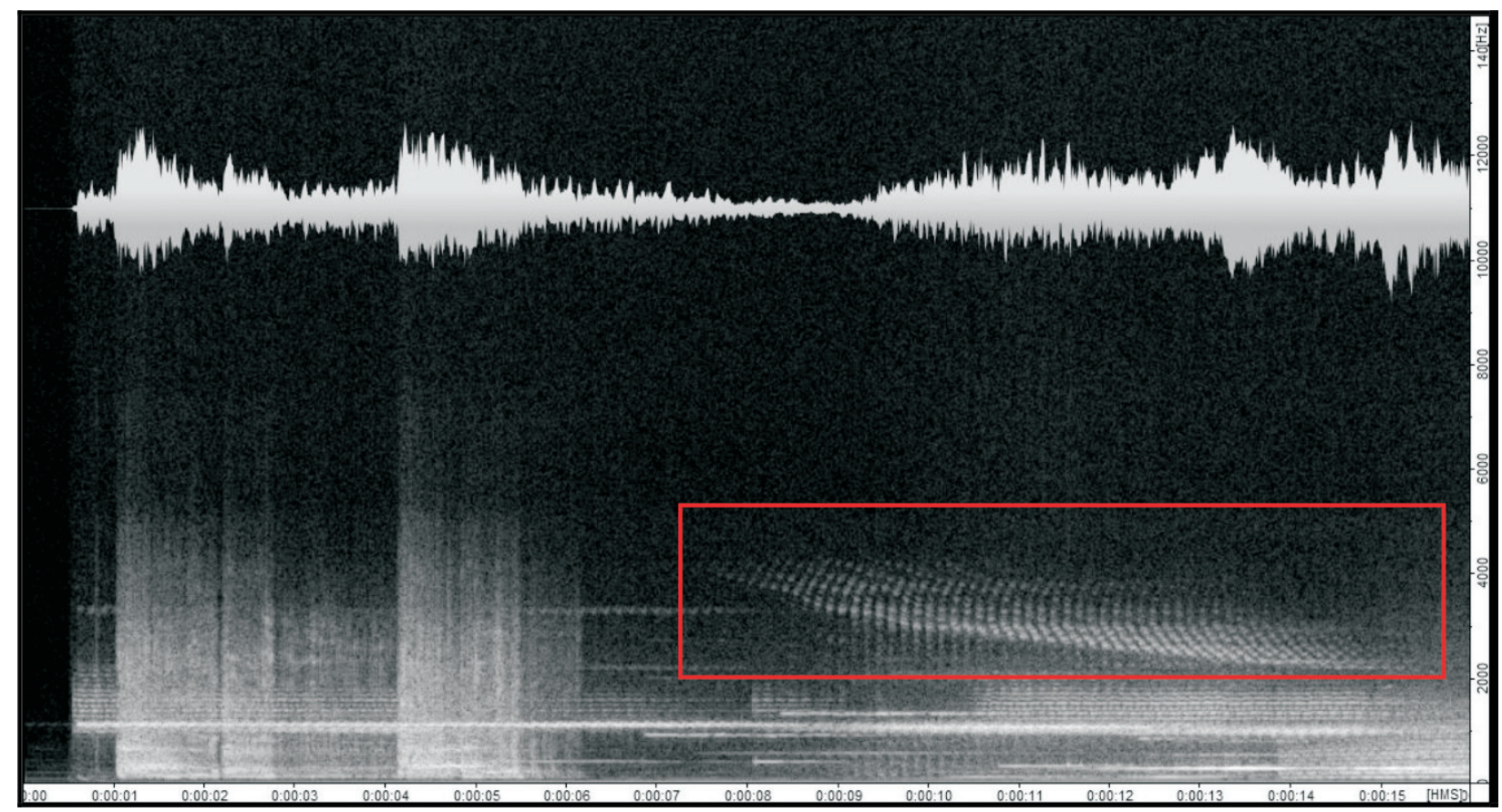

Figura 4: Sonograma4 (acima) e espectrograma (abaixo) do primeiro grupo motívico (0 - 16") da música de abertura de O Planeta Proibido. Em destaque o espectro do objeto sonoro (glissando descendente e com vibrato) que representa o cruzador C57D.

Aproximadamente aos 14 segundos, um segundo grupo motívico - com timbre semelhante a carros de corrida em aceleração e arquétipo continuação gradual - surge em um lento glissando ascendente a partir de um crossfade com o motivo anterior. O glissando é interrompido por um súbito gesto descendente e este movimento é repetido duas vezes, partindo de notas diferentes. Simultaneamente, é apresentado o título do filme, que surge aos poucos em sincronia com os glissandos e, ao se revelar, é acompanhado por uma explosão de efeitos sonoros.

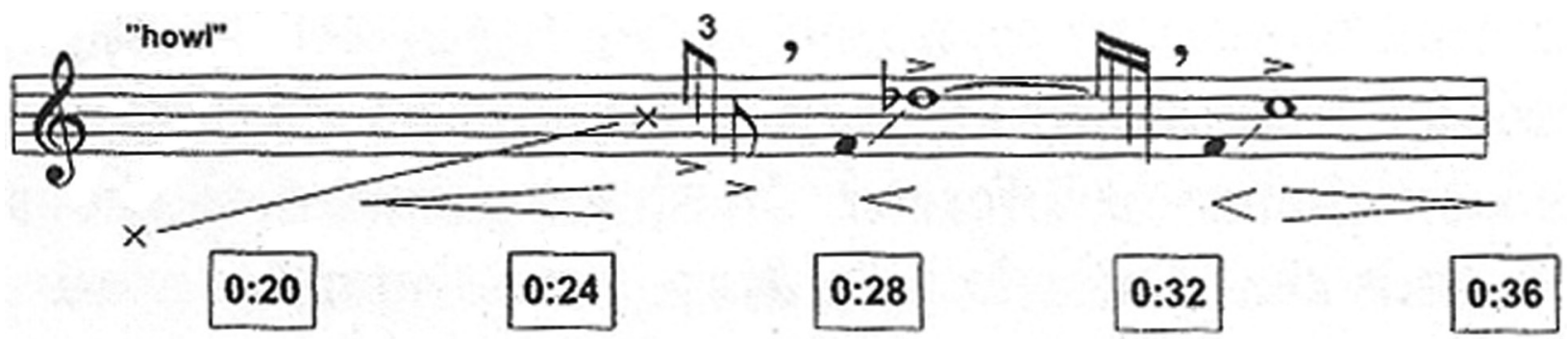

Figura 5: Redução do segundo grupo motívico da faixa de abertura de O Planeta Proibido, segundo Wierzbicki (2005, p. 66). 


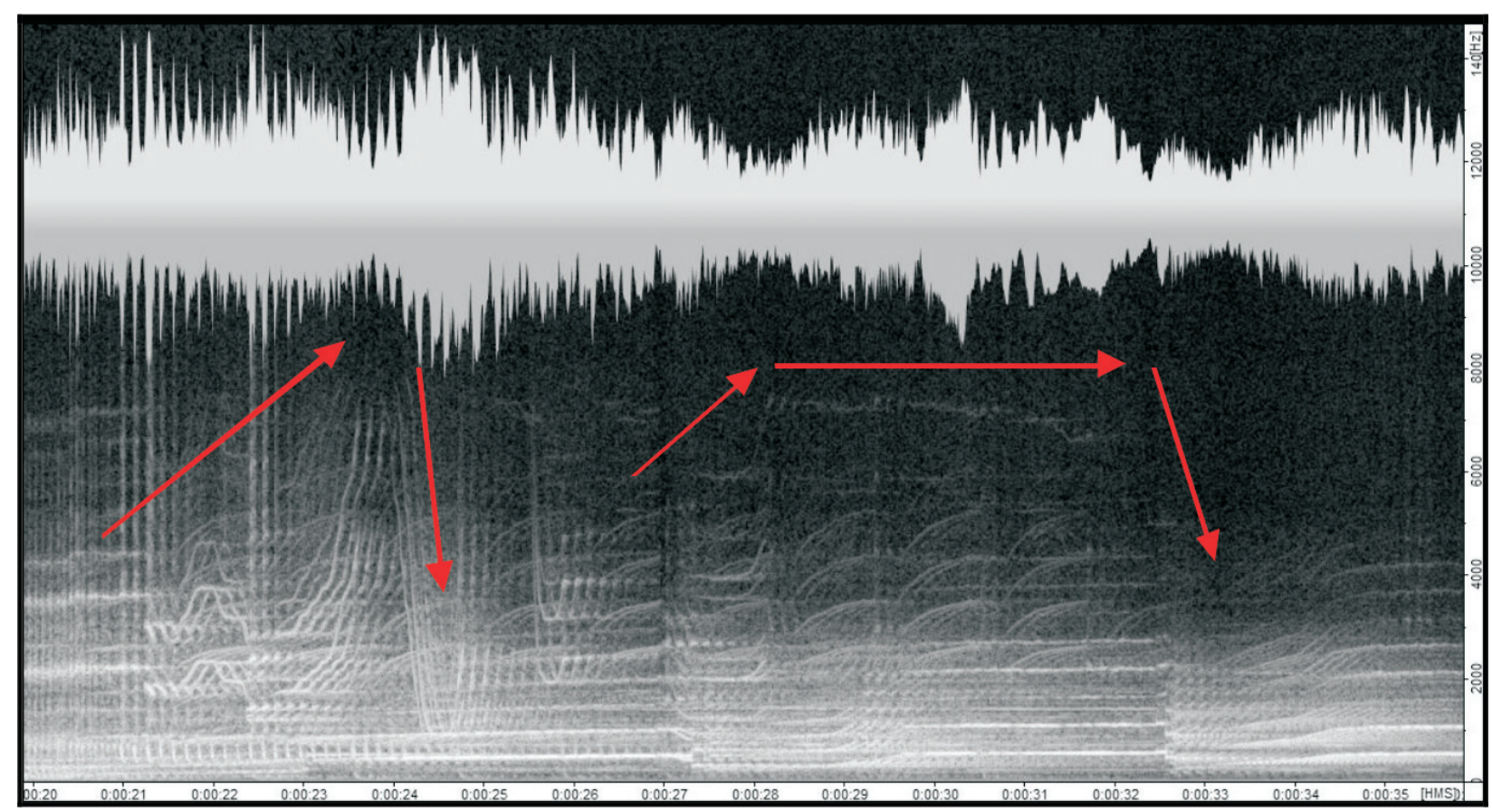

Figura 6: Sonograma e espectrograma do segundo grupo motívico (20" - 36") da faixa de abertura de O Planeta Proibido. As setas destacam o conteúdo espectral do gesto realizado pelo segundo motivo, apresentado em uma redução em partitura na figura 5.

Durante os 20 segundos iniciais, embora os primeiros motivos se apresentem aparentemente sem qualquer relação com a sintaxe tonal, é possível constatar um sentido tonal implícito no material musical, o que sugere uma progressão harmônica sobre a tonalidade de Fá menor. A progressão parte do segundo grau diminuto para o quinto grau da escala de Fá menor, mas, em seguida, esta se dilui na complexidade de texturas e gestos que compõem os demais materiais da trilha sonora.

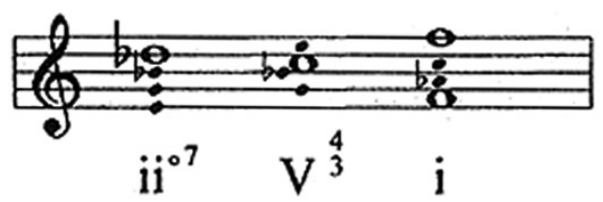

Figura 7: Redução da sintaxe harmônica implícita nos primeiros motivos da música dos créditos iniciais, segundo Wierzbicki (2005, p. 67).

A música dos créditos iniciais faz uso de síntese temática, ou seja, à medida que os créditos se sucedem, são apresentados novos grupos motívicos, de forma a oferecer ao espectador um primeiro contato com os diversos materiais sonoros que permearão o filme. Por volta de 36 segundos, tem início o terceiro grupo motívico, que se relacionará com o Tema de Robby. Este material surge no exato momento em que o nome do personagem robô é apresentado nos créditos. O motivo musical do Tema de Robby desaparece lentamente enquanto outros materiais ganham destaque e se intercalam durante todo o restante da trilha de abertura, formando, assim, uma bricolagem eletrônica que busca inserir o espectador na narrativa futurista que se seguirá. 


\subsection{Temas dos principais personagens}

\subsubsection{Tema de Robby}

O Tema de Robby é formado principalmente por partículas sonoras com arquétipo espectromorfológico ataque-impulso, timbre semelhante a instrumentos de cordas friccionadas tocados em pizzicato e delay ajustado em aproximadamente 54 centésimos de segundo entre uma repetição e outra. As partículas sonoras são atacadas em frequências aparentemente aleatórias, compreendendo todo o espectro, mas com ênfase nas frequências altas, o que confere à trilha uma característica jocosa, indo de encontro à desengonçada personagem (OLIVEIRA, 2011, p. 691-2). Outros materiais se sobrepõem à textura supracitada e, ocasionalmente, atuam como pontuação de determinados diálogos ou gestos dos personagens.

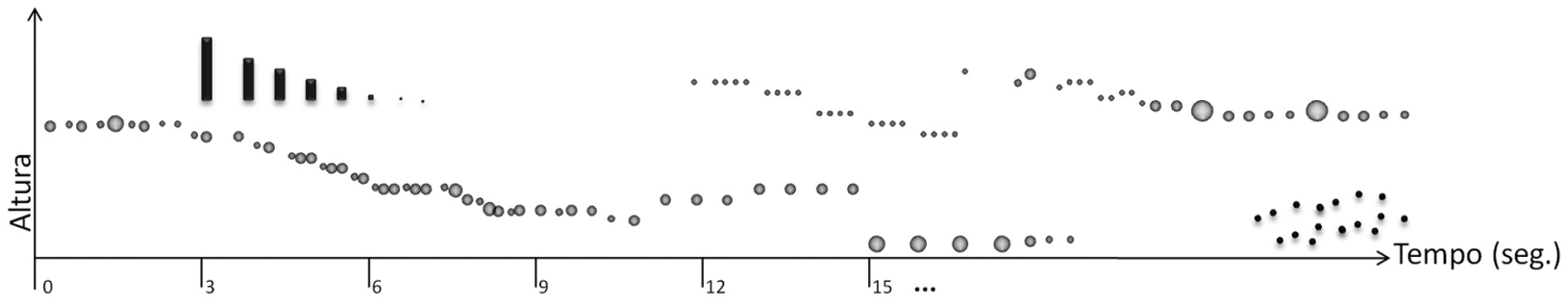

Figura 8: Representação gráfica do Tema de Robby (representação nossa). 0 eixo vertical corresponde à frequência, enquanto o eixo horizontal indica o desenvolvimento temporal. A intensidade é representada pelo tamanho dos objetos. Como é possível observar, o efeito de delay é ilustrado visualmente através da repetição de um mesmo objeto no eixo temporal com seu tamanho se reduzindo gradativamente.

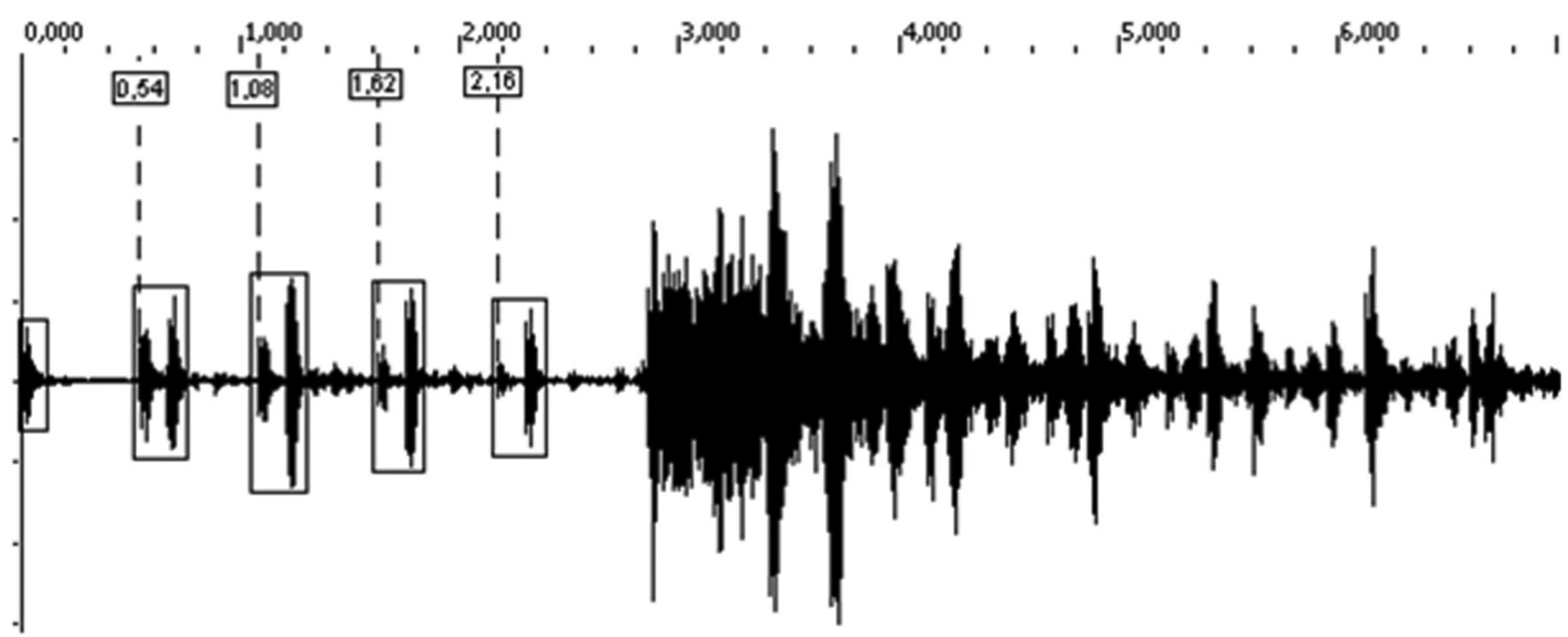

Figura 9: Sonograma dos 6 segundos iniciais do Tema de Robby. 0 efeito de delay é predominante em toda a música. 0 exemplo acima destaca a reiteração (em ataques repetidos) do primeiro objeto sonoro com uma defasagem média de 0,54s entre uma repetição e outra. Pouco antes dos 3s um segundo objeto sonoro, também com efeito de delay, se sobrepõe ao anterior.

\subsubsection{Tema do Monstro do Id}

A distinção entre diegético e extradiegético é especialmente interessante para compreendermos o papel da música nas cenas em que é sugerida a presença do Monstro do Id. Esse personagem é invisível e sua corporificação se dá principalmente através da música, que se associa indicialmente ao som de suas pegadas no solo. A trilha é formada por dois 
materiais principais: 1) lentos ataques na região grave, com arquétipo ataque-decaimento e timbre semelhante ao do estourar de um champanhe; 2) um som com timbre semelhante ao de um theremin ${ }^{5}$, mantido na região aguda, e arquétipo continuação gradual. Os ataques no registro grave possuem o seguinte padrão, que poderá ser representado visualmente no desenho abaixo: um ataque forte seguido de uma reiteração fraca e, após uma pausa curta, outra reiteração fraca. A variação de altura dos ataques proporciona um gradativo aumento de tensão na medida em que o monstro invisível se aproxima. A associação metonímica e metafórica com seus passos remete, ainda, à técnica conhecida como mickeymousing, que consiste em acompanhar musicalmente, ponto a ponto, as ações de um personagem. Em alguns momentos também surge um terceiro som, como uma espécie de humm, com variação ascendente de altura, arquétipo continuação gradual e timbre semelhante a vozes masculinas.

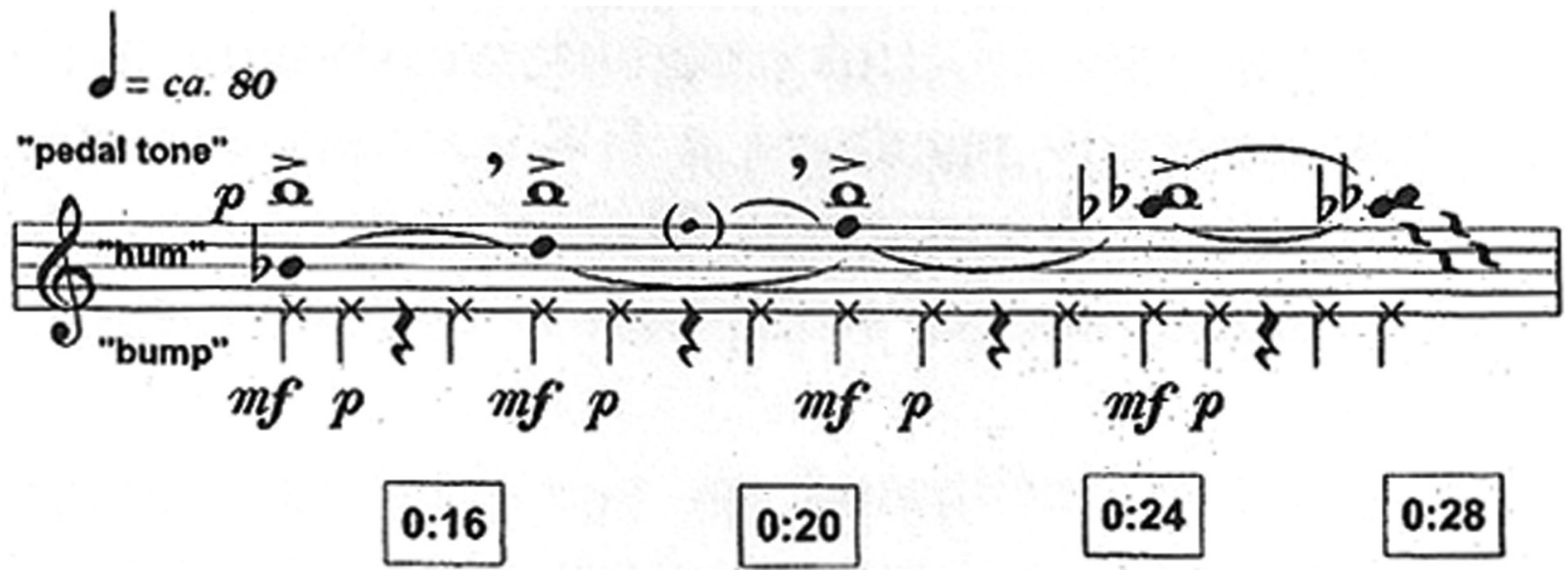

Figura 10: Redução do Tema do Monstro do ld, segundo Wierzbicki (2005, p. 78).

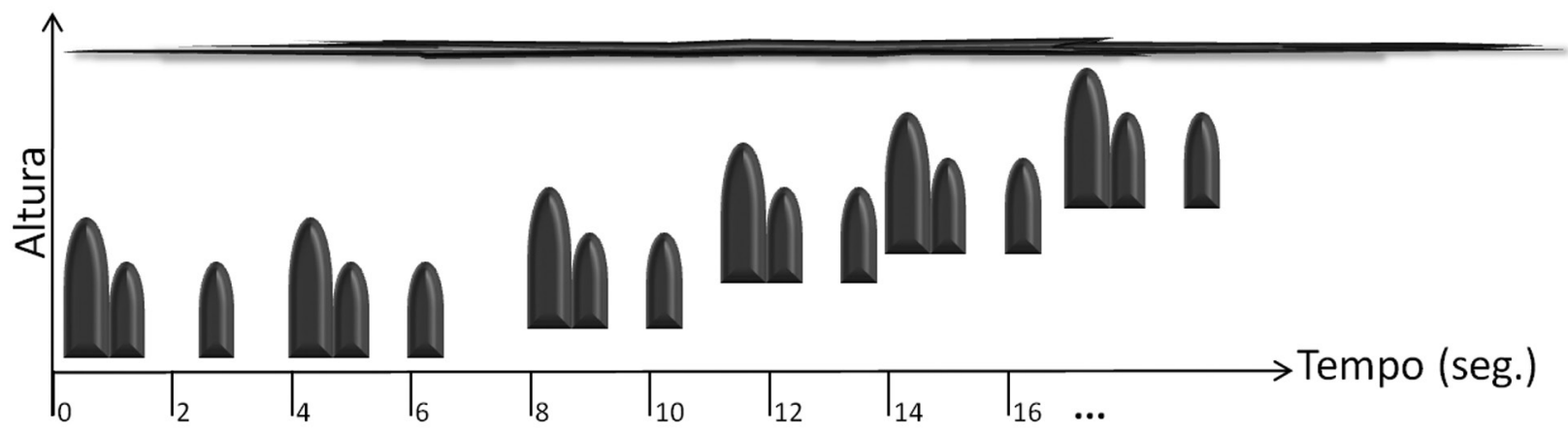

Figura 11: Representação gráfica do Tema do Monstro do ld (representação nossa). A imagem ilustra os ataques na região grave seguidos de repetições mais fracas e sobrepostos a uma frequência contínua. 


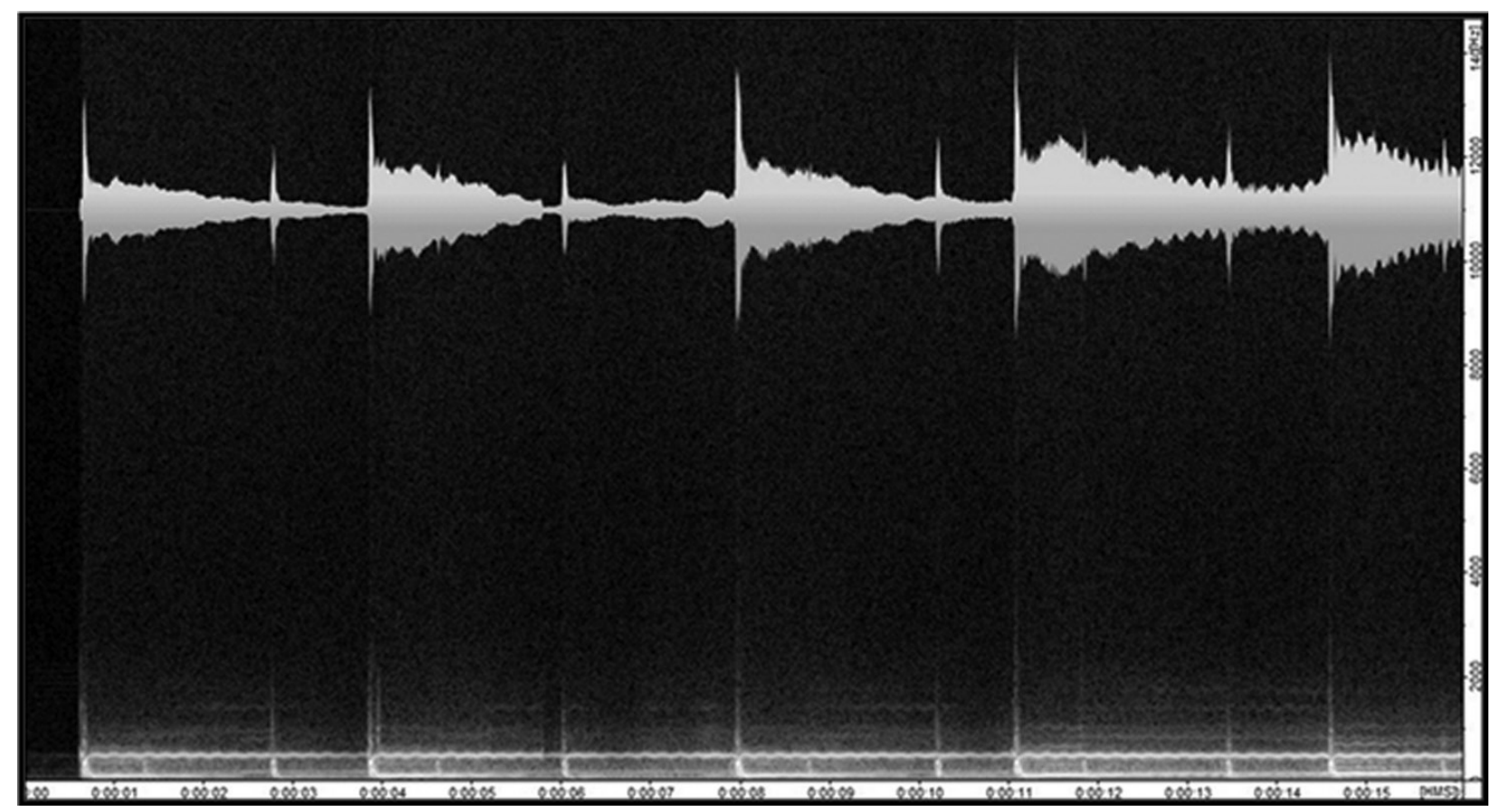

Figura12: Sonograma e espectrograma dos 16 segundos iniciais do Tema do Monstro do ld. É possível observar a correspondência entre o sonograma acima e a representação livre da Figura 11. As regiões com maior concentração de energia correspondem aos ataques, enquanto a faixa branca que perpassa o espectrograma corresponde a uma camada sonora cuja frequência se mantém estável por quase toda a trilha.

\subsubsection{Tema de Altaira}

Esse é o tema romântico do filme. É formado por grupos motívicos heterogêneos, com predominância do arquétipo continuação gradual. Os materiais sonoros que compõem o Tema de Altaira são processados por meio de envelopes e ondas de baixa frequência que atuam sobre os filtros, osciladores e amplificadores. O processamento gera aos efeitos de vibrato, wah-wah, trêmolo e delay que dão origem a uma rica malha sonora de gestos e texturas eletrônicas.

Em contraste com as demais trilhas do filme, [o Tema de Altaira] possui alguma feminilidade: motivos mais "lapidados" e consonantes, gestos melódicos longos, mais voltados para o senso de altura e de timbre que rítmico propriamente dito, o que nos permite relacionar iconicamente ${ }^{6}$ às grandes frases musicais românticas, aos longos suspiros, aos temas líricos - leitmotivs de pares românticos de melodramas da década de 1950. (OLIVEIRA e COELHO DE SOUZA, 2011, p. 691)

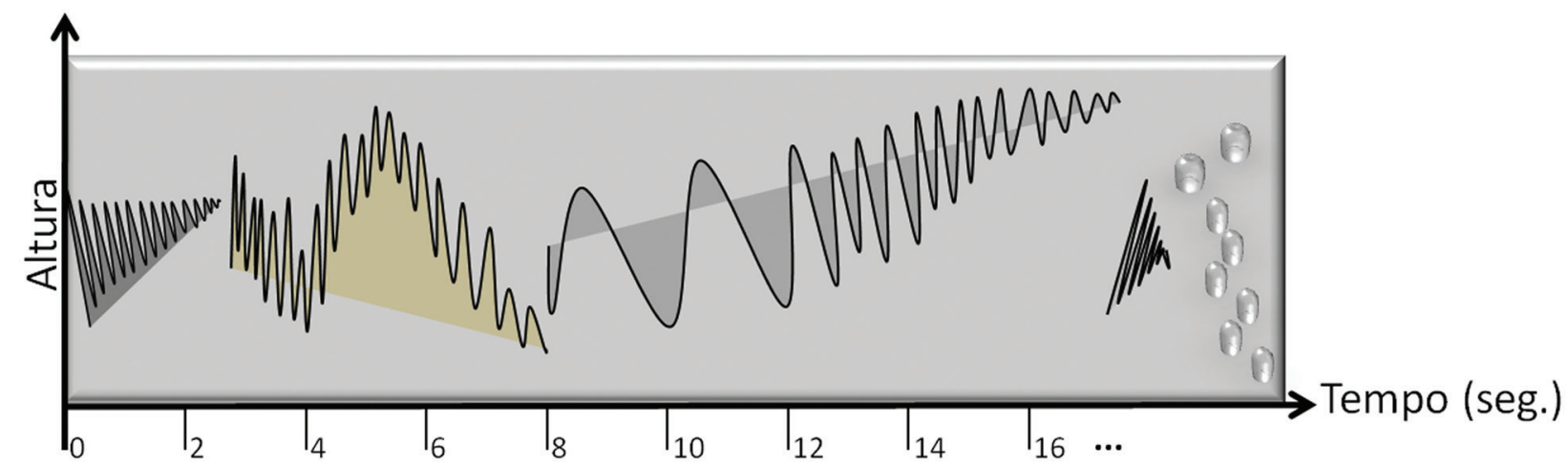

Figura 13: Representação gráfica do Tema de Altaira (representação nossa). 


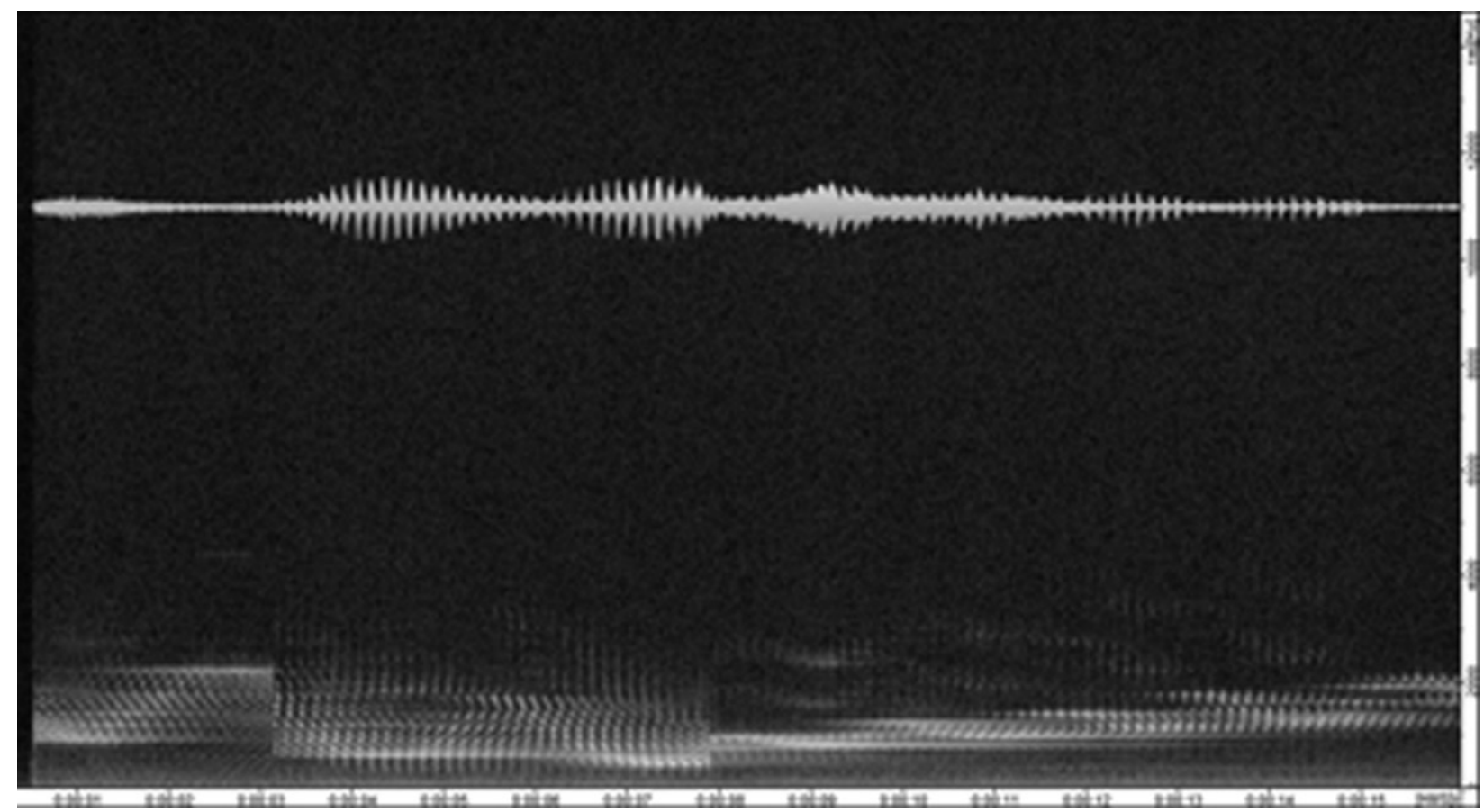

Figura 14: Sonograma e espectrograma dos 16 segundos iniciais do Tema de Altaira. A forma sinuosa do espectro e a variação do conteúdo harmônico apresentados na figura ilustram visualmente o tratamento com ondas de baixa frequência dado aos materiais sonoros da trilha.

\subsection{A música dos Krells}

A última música a ser analisada será o tema dos Krells. Os Krells eram os antigos e avançados habitantes do planeta Altair IV. Em determinado momento do filme, o Dr. Morbius mostra aos astronautas uma gravação musical realizada por músicos Krells há meio milhão de anos. A música é constituída principalmente de dois materiais: 1) gestos melódicos com o arquétipo continuação gradual e timbre semelhante ao de theremins, com um delay de aproximadamente 1,7 segundos; e 2) notas com arquétipo ataque-decaimento fechado e timbre semelhante a um contrabaixo acústico tocado em pizzicato.

A trilha apresenta uma intrincada textura contrapontística, inclusive com seções de imitação e desenvolvimento episódico, apresentando tratamento similar a um ricercare arcaico (LAYDON apud WIERZBICKI, 2005, p. 82).

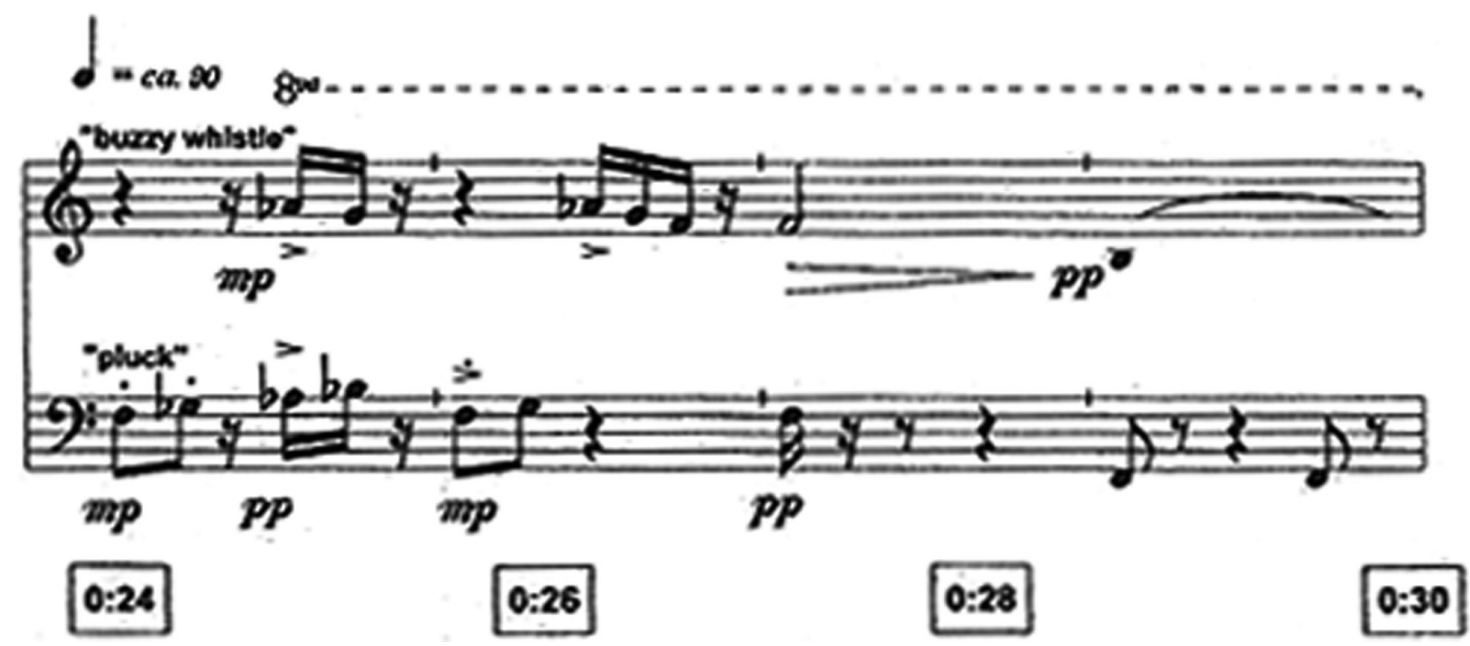

Figura 15: Motivo principal da Música dos Krell, segundo Wierzbicki (2005, p. 83). 


\section{Conclusão}

Os filmes da década de 1950 ajudaram a consolidar a relação de sons eletrônicos com temáticas de distúrbios psicológicos, invasão alienígena, exploração espacial e ameaças de criaturas bizarras. De modo geral, as experiências eletroacústicas no cinema foram associadas a tudo que pudesse ser considerado diferente, anormal e que fugisse dos padrões pré-estabelecidos do espectador médio. Segundo Wierzbicki (2005, p. 24), ocasionalmente, o "outro" se diferenciava dos personagens principais por fatores de classe social, moralidade e instabilidade mental; mas, muito frequentemente, essa diferença era representada pela distinção étnica. Nos primeiros anos de Guerra-Fria, o "outro" representava a ameaça comunista, os soviéticos ou qualquer coisa que questionasse os princípios morais norte-americanos. Esses inimigos eram materializados por meio de vilões monstruosos que ameaçavam colocar em risco a paz dos personagens. A música assumia, assim, uma função indicial de relacionar o estranho no campo auditivo ao grotesco no espaço visual. Com o passar dos anos, a poética composicional, os gestos e a funcionalidade dos primeiros instrumentos eletrônicos no cinema foram repetidos e aperfeiçoados pelas novas invenções, dos sintetizadores às próximas gerações de dispositivos eletrônicos. Desse modo, aos poucos se consolidou uma tradição que relacionaria de forma arraigada a música eletroacústica às narrativas de terror, suspense e ficção científica.

\section{Notas}

1 O filme O cantor de Jazz (The Jazz Singer, 1927) é considerado o marco de origem do cinema sonoro. Alguns meses antes da estreia de O cantor de jazz, o filme Don Juan (1926) já havia sido lançado com som sincronizado através do mesmo sistema Vitaphone. Entretanto, ao contrário daquele, além de não haver som de diálogo sincronizado, a música em Don Juan foi inserida após o filme haver sido concluído.

2 O termo "trilha sonora" abrange todo o universo sonoro de um filme, incluindo folley, diálogos, ruídos de ambientes, efeitos sonoros e música. Observa-se, portanto, que a música ocupa apenas uma das categorias do que denominamos como sendo a trilha sonora de um filme. Por conseguinte, se considera que a expressão "trilha musical" representaria melhor o conteúdo especificamente musical de uma obra audiovisual. No caso de $O$ planeta proibido, entretanto, optamos por adotar deliberadamente a terminologia trilha sonora, ao invés de trilha musical ou simplesmente música, uma vez que a análise leva em conta que o trabalho dos compositores, muitas vezes, dilui os limites de fronteira entre a música e os demais ruídos do filme.

3 Considerando-se o Dó Central como Dó 3.

4 A imagem gráfica (sonograma e espectrograma) foi gerada com o software Acousmographe, desenvolvido pelo INA/GRM (Institut National Audiovisuel, Groupe de Recherches Musicales).

${ }^{5}$ É conveniente enfatizar que o teremin, ou qualquer outro instrumento musical, não foi utilizado na composição da trilha sonora do filme.

6 Primeira categoria da segunda triconomia dos signos proposta por C.S. Peirce: um ícone é "qualquer coisa, seja uma qualidade, um existente individual ou uma lei que seja semelhante de qualquer coisa e utilizada como um signo seu” (PEIRCE, 2010, p. 52 - parágrafo 247).

\section{Referências}

CAPUZZO FILHO, Heitor. Twilight Zone: Combinatórias narrativas e intertextualidade. Dissertação de mestrado. Universidade de São Paulo/ECA. São Paulo, 1988.

CARRASCO, Claudiney. Sygkhronos: a formação da poética musical do cinema. São Paulo: Via Lettera, 2003.

CHION, Michel. A Audiovisão: som e imagem no cinema. Lisboa: Edições Texto e Grafia, 2011. 
EISEINTEIN, Sergei. A forma do filme. Rio de Janeiro: Jorge Zahar, 2002.

GORBMAN, Claudia. Unheard melodies: narrative film music. London: BFI publishing, 1987.

HAYWARD, Philip (ed). Off The Planet: Music, Sound And Science Fiction Cinema. Eastleigh, UK: John Libbey, 2004.

HOLMES, Thom. Electronic and Experimental Music: Technology, Music, and Culture. 3. ed. Routledge, 2008.

IAZZETTA, Fernando. Música e mediação tecnológica. São Paulo: Perspectiva e Fapesp, 2009.

OLIVEIRA, Juliano de; COELHO DE SOUZA, Rodolfo. Análise semiótica da trilha sonora de Forbidden Planet. In: RAY, Sonia (Org.). XXI Congresso da Anppom, p. 689-694. Uberlândia: ANPPOM, 2011.

OLIVEIRA, Juliano. O desenvolvimento da poética eletroacústica na trilha sonora de filmes de ficção científica norte-americanos. Dissertação de mestrado. São Paulo: ECA/USP, 2012.

PEIRCE, Charles S. Semiótica. 4. ed. São Paulo: Perspectiva, 2010.

SMALLEY, Denis. Spectro-morphology and structuring processes. In: EMMERSON, Simon (org.), The language of electroacoustic music, p. 61-93. Nova York: Harwood Academic, 1986.

WIERZBICKI, James Eugene. Louis and Bebe Barron's Forbidden planet: a film score guide. Lanham (MD): The Scarecrow Press, 2005.

\section{Documentos digitais}

CHION, Michel. Guide to Sound Objects: Pierre Schaeffer and musical research. Tradução para o ingles por John Dack e Christine North. Electroacoustic Resource Site: 2009. Disponível em: <http://www.ears.dmu.ac.uk/spip.php?page=articleEars\&id_article=3597>. Acessado em: $24 / 04 / 2012$.

Juliano de Oliveira - Cursa doutorado na ECA/USP com tese intitulada "As bases semióticas da significação musical na trilha sonora cinematográfica”, sob orientação do Dr. Rodolfo Nogueira Coelho de Souza. É professor do curso de música da Universidade Católica de Santos (Unisantos), onde ministra as disciplinas "Música e Tecnologia I e II” e "Música nas Artes Cênicas e Audiovisuais". Pesquisa semiótica e cognição musical e a utilização de instrumentos eletrônicos e música eletroacústica na trilha sonora do cinema.

Rodolfo Coelho de Souza - É professor do Departamento de Música da USP em Ribeirão Preto. Atua nas áreas de Musicologia Analítica, Composição Musical e Tecnologia da Música, pesquisando os seguintes temas: análise de música brasileira do romantismo e modernismo, composição musical auxiliada por computadores, e teorias analíticas da música atonal. Foi coordenador do Lacomus - Laboratório de Computação Musical da UFPR (2001-2004) e atualmente é coordenador do LATEAM - Laboratório de Teoria e Análise Musical do DM-FFCLRP-USP. 